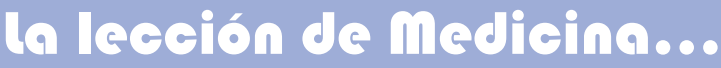

\section{DIEZ RESPUESTAS PUNTUALES SOBRE NEUMONIA ADQUIRIDA EN LA COMUNIDAD EN ADULTOS}

José G. Bustillo P.§§§

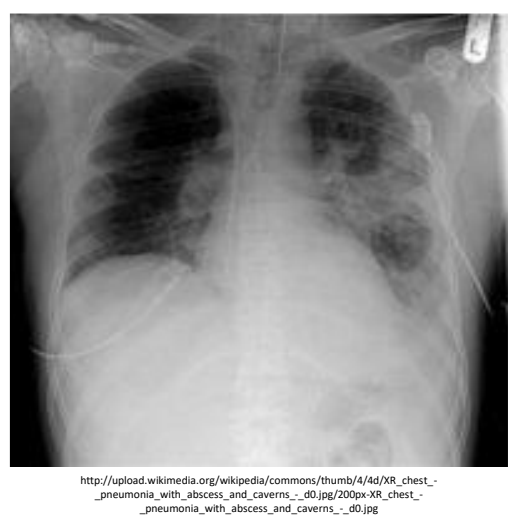

1. ¿En qué consiste la NAC?

La neumonía es una inflamación del parénquima pulmonar desencadenada por diversas especies bacterianas, virus, hongos y parásitos, que se manifiesta por fiebre, tos, estertores y opacidades en la radiografía de tórax. En nuestro país constituye la sexta causa de muerte y la primera por infección.

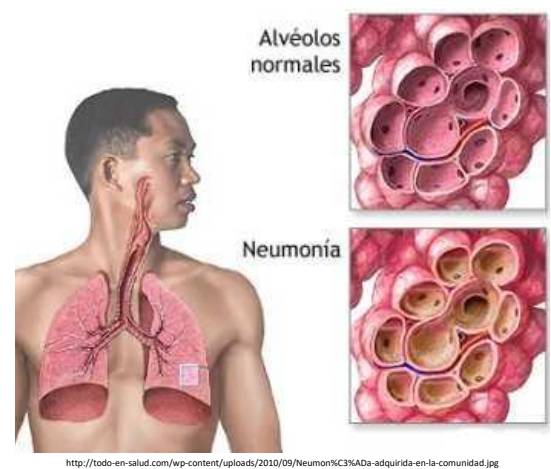

Para catalogarla como "adquirida en la comunidad" (NAC), debe ocurrir en pacientes no hospitalizados o en aquellos hospitalizados que desarrollan manifestaciones dentro de las primeras 48 horas del ingreso (Guías de Neumonía de la Asociación Colombiana de Neumología y Cirugía de Tórax - ACNCT).

§§§ Médico Neumólogo - jose.bustillo@juanncorpas.edu.co. 


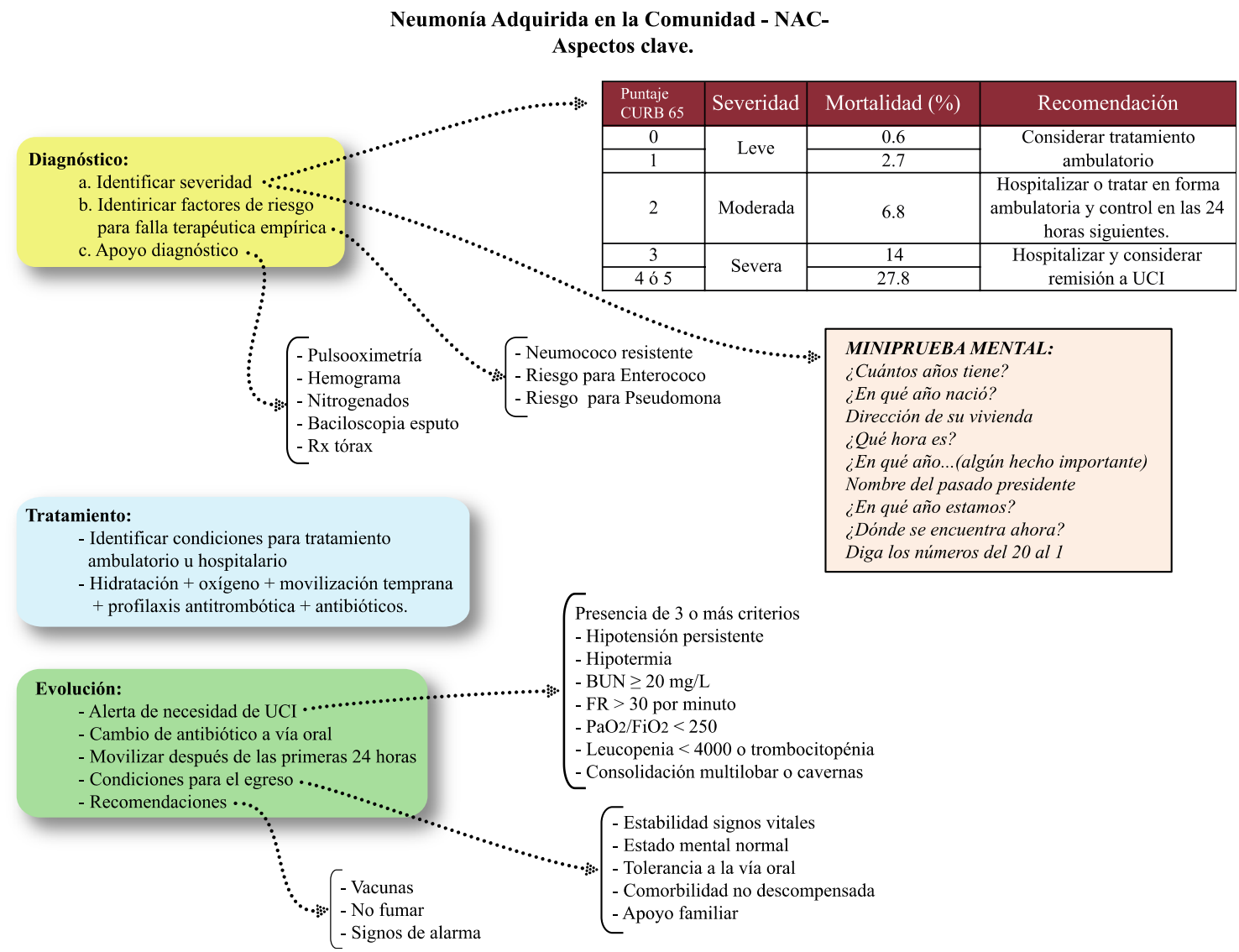

2. ¿Cómo se llega al diagnóstico de NAC?

Por criterios clínicos y radiológicos.

La presencia de fiebre, taquicardia, taquipnea, tos de reciente aparición (con o sin producción de esputo purulento o hemoptoico), estertores inspiratorios y dolor torácico, son los datos clínicos más prevalentes y de fácil identificación en la anamnesis y examen físico $(44,45,46)$. La sensibilidad y especificidad para el diagnóstico de neumonía basado en la presencia conjunta de fiebre, tos y estertores inspiratorios es de $91.7 \%$ y $92.7 \%$ respectivamente (47).

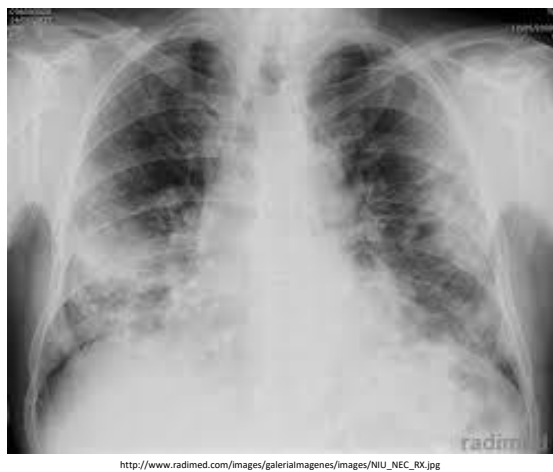


A todo paciente con sospecha de NAC se le debe realizar una radiografía de tórax, tanto para confirmar el diagnóstico como para descartar la existencia de complicaciones. (II A).

Las complicaciones asociadas pueden adoptar la forma de derrame pleural, falla respiratoria, sepsis y shock séptico.

\section{3. ¿Qué se recomienda una vez comprobada la NAC?}

Se recomienda establecer su severidad clínica mediante cualquiera de las escalas disponibles.

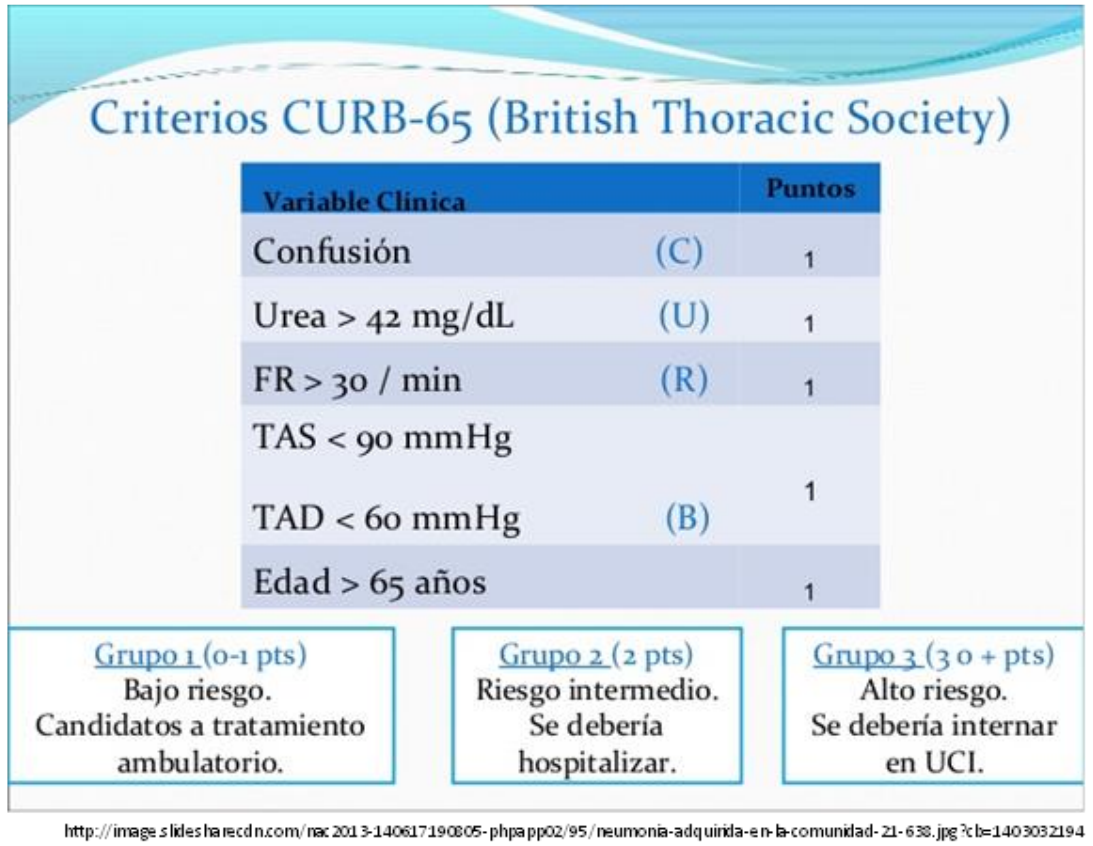

La aplicación de la Escala CURB-65 no solo permite establecer la severidad clínica de la neumonía sino también apoyar la escogencia del antibiótico, aproximarse a un pronóstico y apoyar la decisión del lugar del tratamiento: Ambulatorio u hospitalario y en este último caso, en pisos o en UCI (Nivel de evidencia II - Grado de recomendación A) $(14,15,16)$. El acrónimo CURB 65 deriva de las iniciales de las siguientes palabras:

Confusión (Figura 1) El acierto en la respuesta a cada parámetro da una puntuación de 1, el puntaje $\leq 8$ implica alteración.

Urea (BUN) > $19 \mathrm{mg}$ por $\mathrm{dL}$

Respiración > 30/min.

Blood pressure (PAS $<90 \mathrm{~mm} \mathrm{Hg}$ PAD $<60 \mathrm{~mm} \mathrm{Hg}$ ).

65 años de edad y mayores $(17,24)$.

En la escala de severidad CURB-65, (Figura 1) a cada parámetro se le asigna una puntuación de $\mathbf{0}$ o 1 según si está ausente o presente; la puntuación total va de 0 a 5 y según ella, la NAC se estratifica en tres grupos: leve, moderada y severa. NAC severa se define por un puntaje mayor a 2. 


\section{Hospitalizar}

Las siguientes condiciones también determinan hospitalización en pacientes con NAC:

1. Incapacidad de autocuidado y carencia de soporte familiar.

2. Enfermedades concomitantes como diabetes, nefropatía o hepatopatía crónicas, abuso de alcohol, falla cardíaca, EPOC, neoplasias, desnutrición, ECV y asplenia.

3. Evidencia de sepsis, acidemia metabólica, CID, leucocitos $<4000$ o $>30.000$.

4. Presencia de NAC severa. Este diagnóstico se establece con una sensibilidad del 78 \% y especificidad del $94 \%$ si están presentes dos de los siguientes tres criterios menores: Presión sistólica $<90$ (a pesar de la reanimación hidroelectrolítica apropiada), PaO2/FiO2 < 250 y compromiso multilobar, o si está presente uno de los dos siguientes criterios mayores: Necesidad de ventilación mecánica o shock. La presencia de confusión, alcoholismo activo, hepatopatía crónica, asplenia, leucopenia y cavitaciones pueden indicar manejo en UCI.

\section{4. ¿Cuáles son los gérmenes causantes de NAC?}

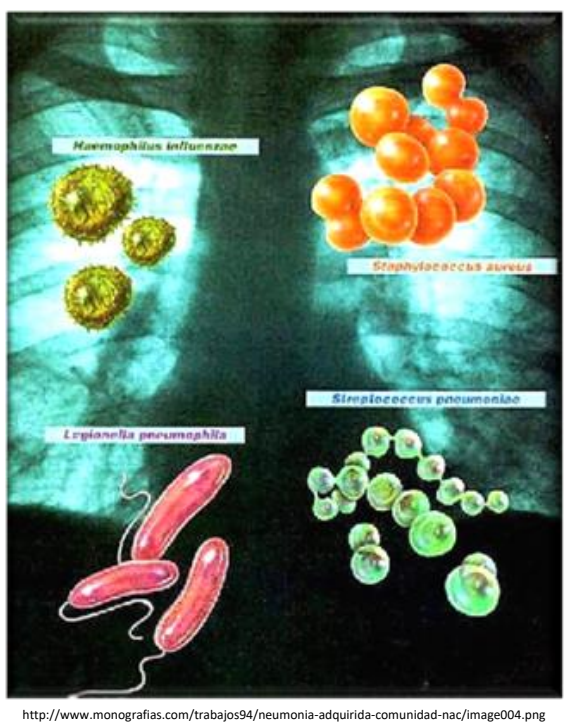

El S. pneumoniae sigue siendo el germen más frecuente implicado en la génesis de la NAC y es probable que responda por el 40 \% que aún no tienen causa microbiológica aparente.

Los gérmenes causantes de la NAC solo se logran identificar en 30-40\% de los casos, pudiendo alcanzarse un $60 \%$ al implementar los métodos convencionales (Gram y cultivo, hemocultivos) con los no rutinarios (serología para Virus, M. pneumoniae, Chlamydophila spp, y Legionella spp, además de detección de antígenos para virus y detección de ag urinario para $S$. pneumoniae, y $L$. pneumophila).

La prevalencia de los gérmenes en cada serie varía de acuerdo a los métodos diagnósticos utilizados y a otros factores como edad, factores de riesgo (tabaquismo, alcoholismo, uso de drogas inhaladas, indigencia, residencia en hogares geriátricos), comorbilidad (EPOC, ICC, IRC, diabetes, neoplasias, ECV, bronquiectasias), uso previo de antimicrobianos y condiciones sociodemográficas. 


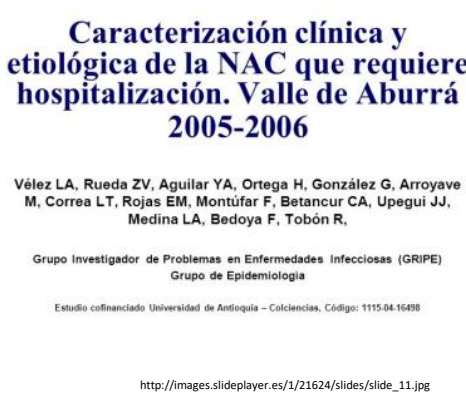

En el trabajo multicéntrico de Vélez y cols, (NAC en el Valle de Aburrá), uno de los trabajos con mayor número de pacientes incluidos, se pudo determinar etiología en $66 \%$ de los casos. Los gérmenes más frecuentes fueron: $S$. pneumoniae 27,6 \%, M. pneumoniae $13,8 \%$, Influenza $A / B 10 \%, C$. pneumoniae 8,7 \%, Adenovirus 7,1 \%, C. burnetii $5.8 \%$, Virus Sincitial Respiratorio (VSR) 4,5 \%, bacilos gram negativos entéricos (Enterobacteriaceae) 3,5 \%, M. tuberculosis 2,9 \%, S., L. pneumophila $2 \%$ y aureus $2,6 \%$. Podemos apreciar que si bien $S$. pneumoniae continúa siendo el principal agente etiológico, existe también evidencia de infecciones por atípicos, virus respiratorios, Bacilos Gram Negativos entéricos y S. aureus. La etiología mixta fue identificada en $22 \%$ de los casos, sin que hasta el momento se haya estudiado la implicación que ello representa para nuestros pacientes (ACNCT).

\section{5. ¿Qué otros estudios paraclínicos adicionales a una radiografía de tórax, SA02, cuadro hemático, nitrogenados y Bk seriado de esputo, pueden ser necesarios en presencia de NAC?}

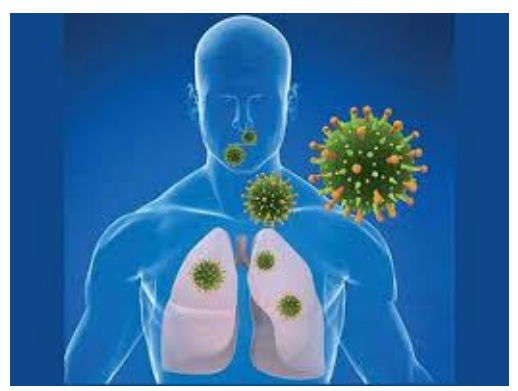

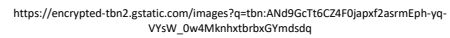

La justificación más clara para pruebas diagnósticas adicionales se encuentra en el paciente críticamente enfermo o con neumonía severa y criterios de hospitalización en UCI. En estos casos el hemocultivo y la obtención de secreciones para gram y cultivo pueden representar beneficio $(56,57$, 58).

Aunque la radiografía no tiene poder para discriminar entre neumonía y otras opacidades alveolares o intersticiales no infecciosas, aporta información sobre la localización y extensión del proceso neumónico, identifica la presencia de derrame pleural o cavitación y sirve de base para evaluar la progresión o la resolución de la enfermedad, todo ello sin desconocer que pequeñas opacidades 
pueden no ser identificables y que la ausencia de anormalidad en la radiografía no elimina la posibilidad de neumonía $(13,48,49,50)$.

Son recomendaciones de las ACNCT al respecto:

\section{Para pacientes del grupo I (ambulatorios)}

A menos que haya situaciones epidemiológicas concretas o de otro orden, no se requieren exámenes adicionales a un hemograma y a una radiografía de tórax.

Para pacientes del grupo II, además de las ayudas diagnósticas ya citadas, se recomienda:

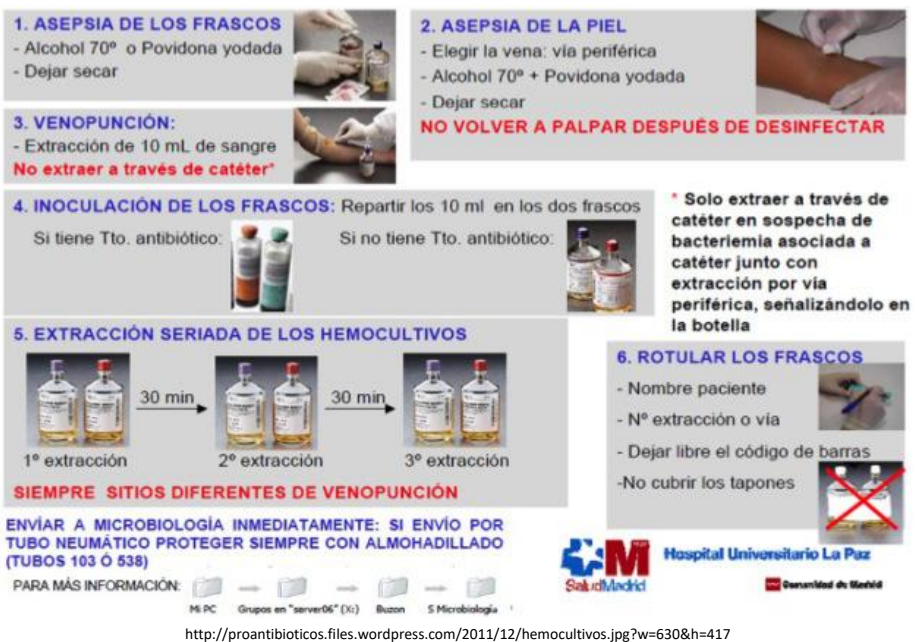

Dos juegos de hemocultivos ( 2 frascos por juego) en pacientes con alcoholismo activo, enfermedad hepática crónica, asplenia, leucopenia, neumonía necrosante, influenza previa o derrame pleural; no es necesario dejar tiempo entre cada juego ni se requiere episodio febril concomitante para su realización.

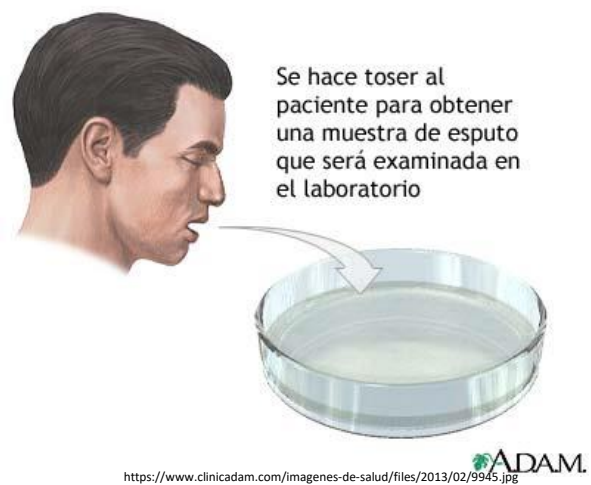

Tinción de Gram y cultivo de esputo $(56,57,58)$.

- Estudio para virus en secreciones respiratorias según recomendaciones epidemiológicas de entes reguladores (Influenza).

- Toracentesis en caso de derrame, con citoquímico, ADA, pH y coloraciones rutinarias. 
Para pacientes del grupo III la ACNCT recomienda:

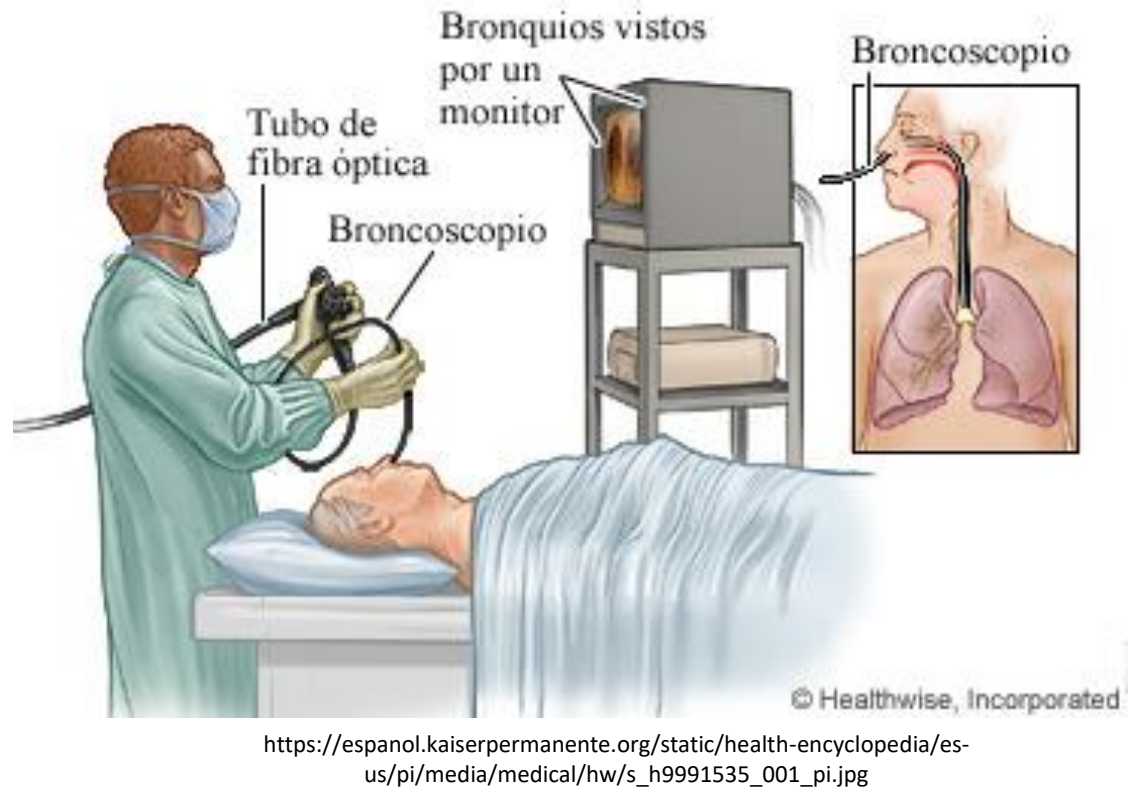

- Broncoscopia para muestra de secreciones de vía aérea inferior, con cultivo cuantitativo.

- Pruebas serológicas en fase inicial y en seguimiento ( 2 a 4 semanas) para atípicos ( $M$. pneumoniae, Legionella spp y C. Pneumoniae), junto con antígeno urinario para Legionella spp y para S. pneumoniae (III).

En pacientes con mala evolución o sospecha clínico-epidemiológica, se recomienda investigar: Virus respiratorios (influenza, sincitial respiratorio, parainfluenza y adenovirus), C. burnetii, C. psitacci y $P$. jirovecci (IIA).

\section{Un cuestionamiento}

Cabe preguntarnos si aparte de estudios con fines epidemiológicos, tiene utilidad la solicitud de paraclínicos en búsqueda de virus y atípicos en pacientes con NAC. En nuestra opinión sería deseable, después de establecida la severidad, identificar el germen causal e iniciar tratamiento. La pregunta sería: Si se identifica el virus, ¿cambiaría eso el curso de la enfermedad? La otra pregunta: Si a los pacientes con NAC severa ya de antemano les administramos macrólidos, para efectos prácticos, ¿qué objeto tiene entonces tratar de establecer la etiología? Una respetuosa propuesta desde estas líneas sería que la ACNCT liderara con sus diversos capítulos, una investigación unificada metodológicamente que permitiera establecer incidencia de atípicos y virus en las diversas regiones del país, así como su impacto en la evolución y respuesta al tratamiento, en el paciente con NAC. 


\section{6. ¿Qué medidas son fundamentales en el tratamiento?}

El tratamiento consta de dos partes:

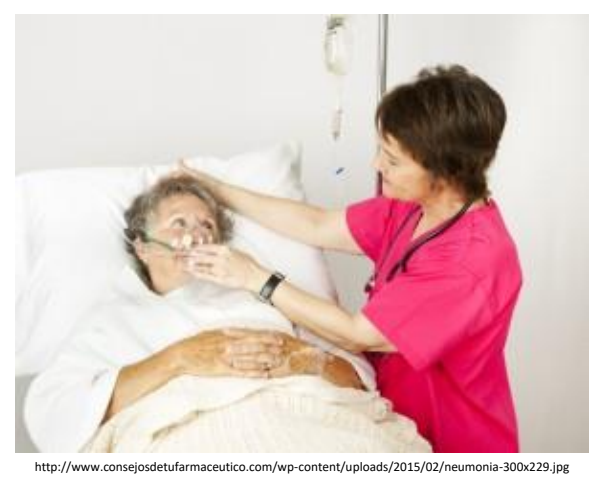

\section{a. Medidas generales.}

- Oxígeno. Asegurar saturación de oxígeno superior a $90 \%$.

La vía y concentración para suministro de oxígeno suplementario está determinado por la condición de cada paciente. (Nivel de evidencia II - Grado de recomendación B) (6).

- Profilaxis antitrombótica venosa según guías disponibles.

- Hidratación Asegurar condición de equilibrio hidroelectrolítico (Nivel de evidencia III - Grado de recomendación B).

- Movilización después de 24 horas. La movilización (traslado de la cama a una silla durante 20 minutos luego de las primeras 24 horas de hospitalización y con incrementos progresivos en los días subsiguientes), ha demostrado reducción de la estancia hospitalaria sin incrementar el riesgo de resultados adversos (Nivel de evidencia II - Grado de recomendación A) (22).

- Monitoría hemodinámica y respiratoria, no invasiva identificar y registrar: estado de conciencia - temperatura- frecuencia cardiaca - frecuencia respiratoria, tensión arterial - oximetría de pulso. Estos datos se toman, registran y analizan al ingreso y, sistemáticamente, cada 4 horas. El intervalo de su registro es modificable según la respuesta clínica.

Verificar condiciones clínicas mínimas para determinar el egreso y para recomendar los días y vía de administración de antibiótico (Nivel de evidencia II - Grado de recomendación B) (35, $36,37,38)$.

\section{- Manejo de comorbilidades si las hubiere.}

b. Administración de antibióticos. Se define de acuerdo a severidad, epidemiología local y regional, riesgos asociados para falla terapéutica y lugar apropiado para realizar el tratamiento. Se recomienda iniciar dentro de las primeras cuatro a seis horas del ingreso o una hora después del mismo en casos de neumonía grave. Otras guías recomiendan Iniciar dentro de las primeras 8 horas posteriores al diagnóstico. (Nivel de evidencia II - Grado de recomendación B) (23, 25, $26,27,28,29,30,31,51)$. 
A continuación, se muestra al lector el esquema basado en las Guías de NAC de la Clínica Corpas y como otra alternativa, el esquema propuesto por la ACNCT.

\section{ESQUEMA DE TRATAMIENTO BASADO EN LAS GUÍAS INSTITUCIONALES DE LA CLÍNICA CORPAS}

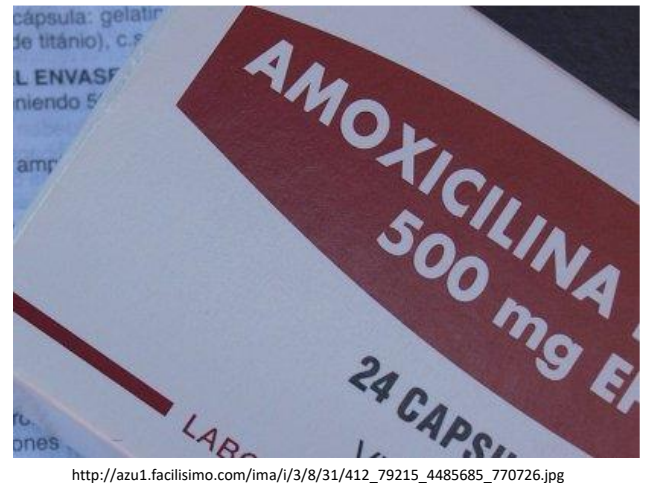

\section{Tratamiento Grupo I (extrahospitalario)}

Primera opción. Amoxicilina 500 miligramos tres veces al día, por 5-7 días* (Nivel de evidencia I Grado de recomendación A).

Alternativa. Claritromicina 500 miligramos dos veces al día, por 5-7 días* (Nivel de evidencia II Grado de recomendación B) o Doxicilina 200 miligramos dosis inicial y luego 100 miligramos día por 5 -7 días*. (Nivel de evidencia III-Grado de recomendación B).

\section{Tratamiento Grupo II (hospitalizado en salas)}

Primera opción. Amoxicilina/clavulanato, 875 /125 miligramos tres veces día por 5-7 días* (Nivel de evidencia I - Grado de recomendación A)

Ampicilina/sulbactam 1,5 gramos tres veces por día iv 5-7 días Nivel de evidencia I - Grado de recomendación A)

Alternativa. Ceftriaxona, $1 \mathrm{~g}$ diario intravenoso 5-7 días Levofloxacina, $750 \mathrm{mg}$ diarios vía oral 5-7 días Moxifloxacina, 400 mg diarios vía oral 5-7 días (Nivel de evidencia I - Grado de recomendación A)

\section{Tratamiento Grupo III (hospitalizado en UCI)}

Primera opción. Amoxicilina 500 miligramos cuatro veces al día junto con claritromicina 500 miligramos dos veces al día; ambos por 7-10 días (Nivel de evidencia I - Grado de recomendación A).

\section{Si la vía oral no es posible:}

Amoxicilina/clavulanato, 1000 /200 miligramos cuatro veces día junto con claritromicina 500 miligramos dos veces al día; ambos por 7-10 días, iv por 7-10 días (Nivel de evidencia I - Grado de recomendación A) o...

Ampicilina/sulbactam 1,5 gramos cuatro veces por día junto con claritromicina 500 miligramos dos veces al día; ambos por 7-10 días, iv por 7-10 días. (Nivel de evidencia I - Grado de recomendación A) 
Alternativa. Ceftriaxona, 1 gramo al día más claritromicina 500 miligramos dos veces al día; ambos por 7-10 días iv. (Nivel de evidencia II - Grado de recomendación B)

(Nivel de evidencia I - Grado de recomendación A), o...

Piperacilina/tazobactam 4,5 gramos tres veces al día junto con amikacina 15 miligramos/kg/día junto con levofloxacina 750 miligramos al día iv, 7-10 día. (Nivel de evidencia I - Grado de recomendación A).

Alternativa. Ceftazidime, 2 gramos tres veces al día junto con amikacina $15 \mathrm{mg} / \mathrm{kg} / \mathrm{día}$ junto con levofloxacina 750 miligramos al día iv, 7-10 días (Nivel de evidencia II - Grado de recomendación B) (si no está disponible levofloxacina se puede administrar ciprofloxacina $400 \mathrm{mg}$ tres veces por día iv).

\section{Uso de antivirales-ACNCT}

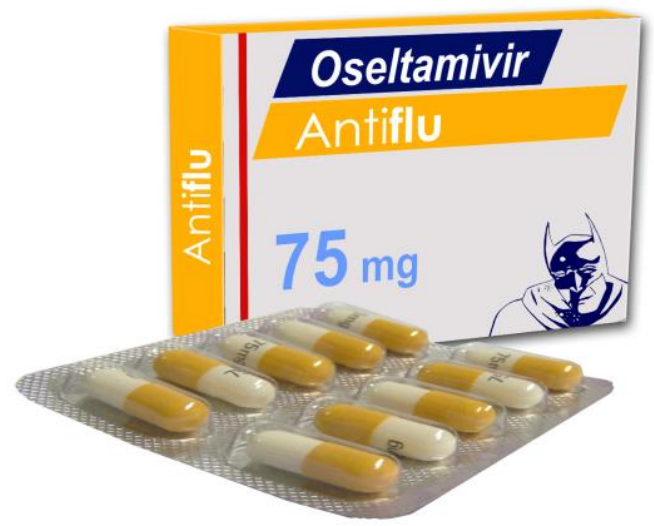

https://badmanbarcelona.files.wordpress.com/2010/01/foto-caja-ybllister_oseltamivir3-badman.jpg

Las recomendaciones actuales en Colombia indican el uso de oseltamivir en todos los pacientes con diagnóstico de neumonía grave adquirida en la comunidad. La recomendación del uso de antivirales debe ir en conjunto con la alerta epidemiológica realizada por las autoridades de salud.

\section{ESQUEMA DE TRATAMIENTO BASADO EN LAS GUÍAS DE LA ACNCT}

Grupo I: puntaje entre 0 y 1 en la escala CRB-65 o CURB-65.

a) Sano sin factores de riesgo:

\section{Tratamiento ambulatorio}

Primera línea (evidencia IA):

- Amoxicilina, $1 \mathrm{~g}$ por vía oral, cada $8 \mathrm{~h}$, o claritromicina, $500 \mathrm{mg}$ por vía oral, cada 12 horas, o azitromicina, $500 \mathrm{mg}$ diarios, por vía oral.

Alternativas:

- Doxiciclina, $100 \mathrm{mg}$ por vía oral, cada 12 horas (evidencia IIB).

- En casos de alergia a las penicilinas, intolerancia a los macrólidos o a las tetraciclinas se debe considerar moxifloxacina, $400 \mathrm{mg}$ al día por vía oral, o levofloxacina, 750mg/día por vía oral (evidencia IA). 
b) Con factores de riesgo o enfermedades concomitantes:

Duración del tratamiento. En términos generales está entre cinco a siete días. Mycoplasma, Legionella y Chlamydia pueden requerir 10-14 días. En NAC por S. aureus, la terapia puede extenderse según la respuesta y presencia de complicaciones, a 14-21 días. Cuando se utilice azitromicina, el tratamiento debe ser por tres a cinco días.

\section{Tratamiento ambulatorio}

Primera línea (evidencia IA):

- Amoxicilina-ácido clavulánico, $1 \mathrm{~g}$ por vía oral, cada 12 horas, asociado a claritromicina, $500 \mathrm{mg}$ por vía oral, cada 12 horas o azitromicina 500 mg diarios vía oral.

Alternativa:

- Cefuroxima, 500 mg por vía oral, cada 12 horas, asociado a claritromicina, 500 mg por vía oral, cada 12 horas (evidencia IA).

- En caso de alergia a las penicilinas o intolerancia a los macrólidos, fluroroquinolonas: moxifloxacina, $400 \mathrm{mg}$ al día por vía oral, o levofloxacina, $750 \mathrm{mg}$ al día por vía oral (evidencia IA).

Grupo II: puntaje de 2 en la escala CRB-65 o CURB-65.

a) Sin factores de riesgo y sin enfermedades concomitantes.

\section{Hospitalización en sala general (Fuera de la unidad de cuidados intensivos)}

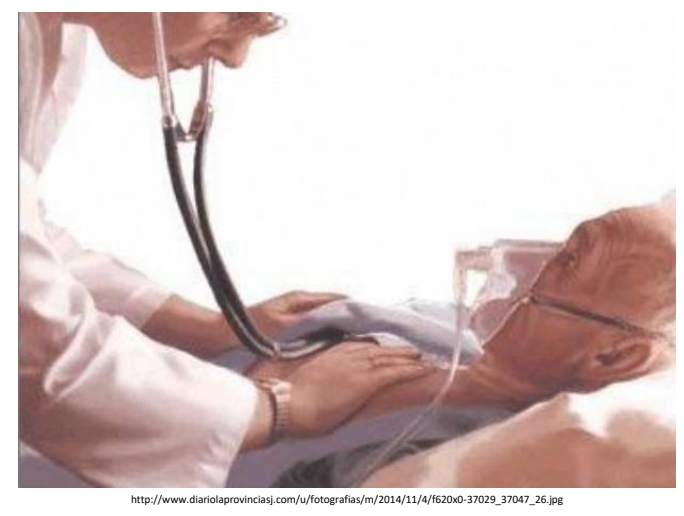

Primera línea: betalactámico más macrólido (evidencia IA):

- Penicilina cristalina, 2 millones de unidades, intravenosos cada 4 horas, más claritromicina, 500 mg intravenosos cada 12 horas.

Alternativas:

- Ampicilina, $2 \mathrm{~g}$ intravenosos cada 4 horas más claritromicina, 500 mg intravenosos cada 12 horas (evidencia IIB).

- En pacientes alérgicos a las penicilinas (evidencia IA): Quinolona 'respiratoria', intravenosa: moxifloxacina, $400 \mathrm{mg}$ diarios, intravenosos, o levofloxacina, $500 \mathrm{mg}$ diarios, intravenosos. 
b) Con factores de riesgo o enfermedades concomitantes.

\section{Hospitalización en sala general (Fuera de la unidad de cuidados intensivos)}

Primera línea (evidencia IA):

- Ampicilina-sulbactam, $3 \mathrm{~g}$ intravenosos acada 6 horas, más claritromicina, $500 \mathrm{mg}$ intravenosos cada 12 horas.

Alternativa (evidencia IIA):

- Cefuroxima, $750 \mathrm{mg}$ intravenosos cada 8 h más claritromicina 500 mg intravenosos cada 12 horas.

- En pacientes alérgicos a las penicilinas (evidencia IA):

- Quinolona "respiratoria", intravenosa: moxifloxacina, 400 mg diarios, intranosos.

- Levofloxacina $500 \mathrm{mg}$ diarios IV.

c) Con factores de riesgo para neumococo resistente a la penicilina.

\section{Hospitalización en sala general \\ (Fuera de la unidad de cuidados intensivos)}

En caso de sospecha de neumococo resistente a la penicilina (evidencia IA):

- Ceftriaxona, 2 g diarios, intravenosos, más claritromicina, 500 mg intravenosos cada 12 horas.

- En pacientes alérgicos a las penicilinas:

Quinolona 'respiratoria', intravenosa: moxifloxacina, $400 \mathrm{mg}$ diarios, intravenosos, 0 levofloxacina, $500 \mathrm{mg}$ diarios, intravenosos.

d) Hospitalización por razones socioeconómicas.

\section{Hospitalización en sala general (Fuera de la unidad de cuidados intensivos)}

Tratamiento igual al del grupo IA

Grupo III: puntaje de tres o más en CRB-65 O CURB-65 MÁS CRITERIOS ats/IDSA para ingreso a la unidad de cuidados intensivos (neumonía grave adquirida en la comunidad).

a) Sin factores de riesgo para P. aeruginosa. 


\section{Hospitalización en la unidad de cuidados intensivos}

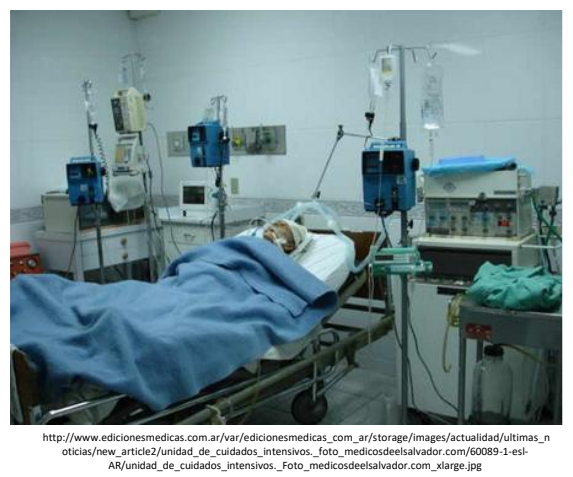

Primera línea:

- Ampicilina-sulbactan, $3 \mathrm{~g}$ intravenosos cada 6 horas, más claritromicina, 500 mg intravenosos cada 12 horas, más oseltamivir más vancomicina o linezolid.

Alternativas:

- Cefuroxima, 750 mg intravenosos, cada 8 h, más claritromicina, 500 mg intravenosos cada 12 h, más oseltamivir, 75 mg cada 12 horas más vancomicina o linezolid.

En pacientes alérgicos a la penicilina usar: fluroquinolona moxifloxacina, $400 \mathrm{mg}$ diarios intravenosos, o levofloxacina, $500 \mathrm{mg}$ diarios intravenosos, más oseltamivir, $75 \mathrm{mg}$ cada 12 horas más vancomicina o linezolid.

b) Con factores de riesgo o para P. aeruginosa.

\section{Hospitalización en la unidad de cuidados intensivos}

Primera línea:

- Piperacilina-tazobactam, 4,5 g intravenosos cada 6 horas, más claritromicina, 500 intravenosos cada 12 horas, más oseltamivir, 75 mg cada 12 horas.

Alternativa:

- Cefepima, 2 g intravenosos cada 8 h, más claritromicina 500 mg intravenosos cada 12 horas, más oseltamivir, $75 \mathrm{mg}$ cada 12 horas.

c) Con factores de riesgo.

S. aureus resistente a la meticilina.

\section{Hospitalización en sala general (Fuera de la unidad de cuidados intensivos)}

Primera línea:

- Ampicilina-sulbactam, $3 \mathrm{~g}$ intravenosos cada seis horas, más claritromicina, $500 \mathrm{mg}$ intravenosos cada 12 horas, más vancomicina (dosis de carga: $25 \mathrm{mg} / \mathrm{kg}$ y luego $15 \mathrm{mg} / \mathrm{kg} / 12 \mathrm{~h}$ ) o linezolid, $600 \mathrm{mg}$ intravenosos cada 12 horas más oseltamivir, 75 mg cada 12 horas.

Alternativa:

- Piperacilina-tazobactam, 4,5 g intravenosos cada seis horas, más claritromicina, $500 \mathrm{mg}$ intravenosos cada 12 horas, más linezolid o vancomicina, más oseltamivir, $75 \mathrm{mg}$ cada 12 horas.

- Cefepima, 2 g cada ocho horas, más claritromicina, 500 mg intravenosos cada 12 horas, más vancomicina o linezolid más oseltamivir, $75 \mathrm{mg}$ cada 12 horas. 


\section{7. ¿Debería el tratamiento empírico incluir antibióticos para atípicos en todos los pacientes hospitalizados con NAC?}

Para efectos prácticos y con base en la información disponible, es procedente iniciar tratamiento empírico sin considerar incluir antibióticos para gérmenes atípicos, a menos que las condiciones clínicas específicas del caso orienten o apunten claramente a la participación de un germen atípico. Es relevante tener presentes los resultados de la revisión sistemática de Eliakim-Raz Noa y cols (23) que congrega 28 ensayos clínicos, con 5.939 pacientes asignados al azar a tratamiento con esquema antibiótico para gérmenes atípicos o esquema antibiótico sin incluir fármacos para estos últimos. No hubo diferencia significativa entre la mortalidad del brazo atípico y el brazo no atípico (RR 1,14; IC del $95 \%: 0,84$ a 1,55). En el grupo de pacientes tratados con esquema antibiótico que incluyó medicamentos para gérmenes atípicos se identificó una exigua tendencia a mejores resultados clínicos y ventaja significativa en la erradicación bacteriológica. Esta última ventaja no fue posible evidenciarla cuando se incluyeron para el análisis sólo estudios de alta calidad metodológica. No hubo diferencias entre los grupos en cuanto a la frecuencia de los eventos adversos. Así pues, con base en este estudio, no es recomendable apoyar la inclusión de antibióticos para gérmenes atípicos en el tratamiento empírico de la neumonía adquirida en comunidad.

Los macrólidos claritromicina y azitromicina, así como fluoroquinolonas, son opciones terapéuticas válidas; no obstante, no han demostrado mayor eficacia en comparación con amoxicilina para el tratamiento de neumonía comunitaria no complicada $(29,30)$. La ACNCT recomienda en la medida de lo posible, evitar la utilización empírica de quinolonas y cefalosporinas de tercera generación ya que este grupo de antibioticos está implicado en la aparición de resistencia. Además, el abuso de quinolonas puede causar resistencía a M. tuberculosis.

Si el paciente requiere tratamiento hospitalario la penicilina intravenosa puede ser una alternativa. Las penicilinas son extensamente utilizadas para tratar pacientes con NAC dada su seguridad y eficacia comprobada y economía y permanecen dentro de recomendaciones en guías de práctica en diferentes países. $(3,65)$.

\section{Escogido el posible antibiótico, ¿qué o cuáles riesgos asociados a falla terapéutica empírica, se deben identificar?}

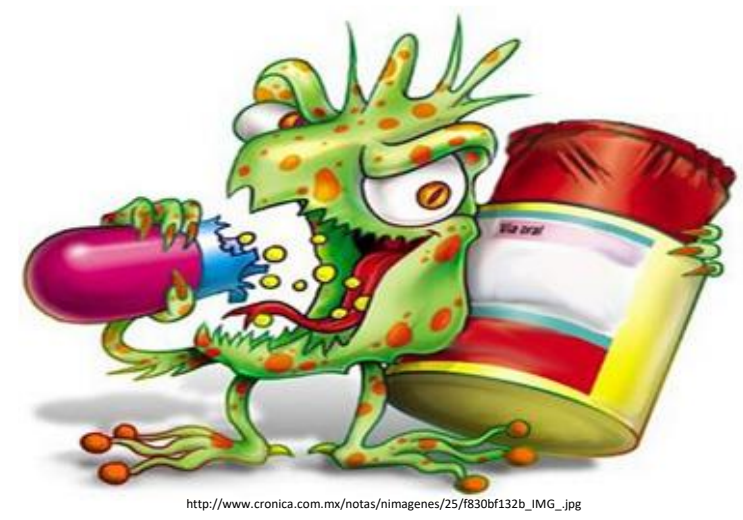

\section{a. -NAC por Streptococcus pneumoniae resistente}

La resistencia del S. pneumoniae a los antibióticos se asocia con edad mayor de 65 años, administración de beta-lactámicos en los últimos tres meses, inmunosupresión (ya sea como 
resultado de una enfermedad o inducida por el tratamiento con corticosteroides), múltiples comorbilidades médicas, alcoholismo y la convivencia en hacinamiento $(21,59,60)$.

\section{b. -NAC por Enterococos gram negativos}

Entre los factores de riesgo para considerar a los enterococos gram (-) como productores de la NAC, se cuentan la antibiotioterapia previa, enfermedad subyacente cardiopulmonar, residencia en un hogar de ancianos, y múltiples comorbilidades médicas.

\section{C. -NAC por $P$. aeruginosa}

Los factores de riesgo para $P$. aeruginosa consisten en enfermedad pulmonar estructural tales como bronquiectasias; administración de antibiótico de amplio espectro con duración de al menos siete días en el mes previo, corticosteroides (con al menos $10 \mathrm{mg}$ de prednisona por día) y la mal nutrición (61), vivir en hogares comunitarios y el hacinamiento.

\section{9. ¿Qué se puede destacar respecto a grupos especiales en NAC? (ACNCT)}

\section{NAC por neumococo}

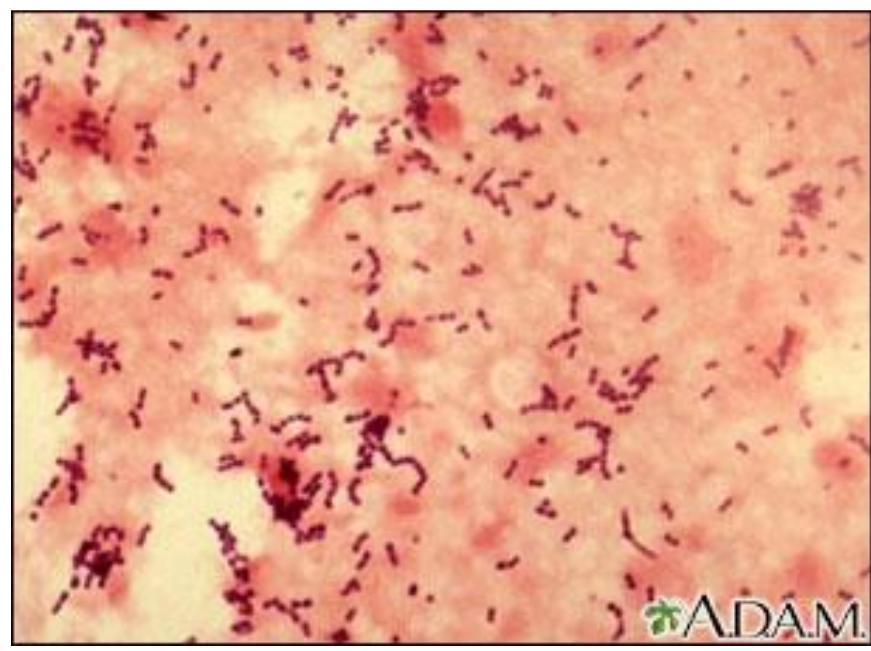

http://www.nlm.nih.gov/medlineplus/spanish/ency/images/ency/fullsize/2928.jpg

Aparte de las pruebas rutinarias, el diagnóstico de neumococo puede hacerse también por demostración de antígeno urinario. Esta prueba detecta el polisacárido $\mathrm{C}$ del neumococo, que se encuentra en la pared celular y es común a todos los serotipos. Es una prueba rápida con una sensibilidad que oscila entre 52-80 \%, con un VPP de $50 \%$ y VPN de $95 \%$. La sensibilidad aumenta en quienes presentan bacteremia, no han recibido antibiótico o tienen cultivo de esputo positivo.

La resistencia del Streptococcus pneumoniae: la única población en la que realmente se ha demostrado un alto impacto del neumococo resistente es en la población VIH con NAC y bacteremia asociada (61). 


\section{NAC por gérmenes atípicos}

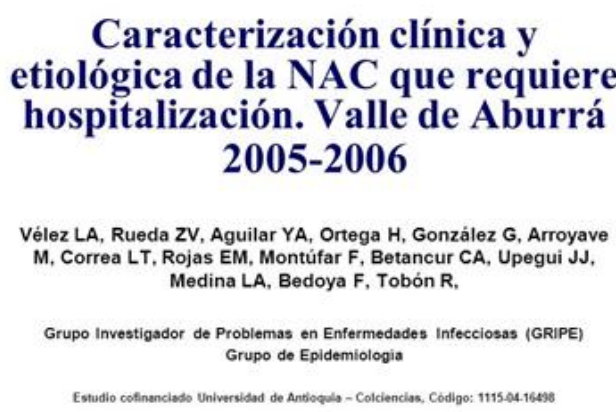

Estudios multicéntricos locales en el valle de Aburrá, dan cuenta de la presencia de atípicos con porcentajes comprendidos entre $14-26,7 \%$

El excluir contacto con aves, gatos, ovejas o conejos, permite dejar a un lado las posibilidades de psitacosis (Chlamydia psitacci), fiebre Q (Coxiella burnetii) o tularemia (Francisella tularensis), para considerar como posible etiología a M. pneumoniae, Chlamydophila pneumoniae y L. pneumophila).

La exposición a fuentes de agua contaminadas en edificios, hoteles u hospitales con compromiso multisistémico grave, hace pensar en L. pneumophila), microorganismo que al parecer no se trasmite de persona a persona.

M. pneumoniae y Chlamydophila pneumoniae predominan en niños y adultos jóvenes y se trasmiten de persona a persona, en entornos comunitarios cerrados (colegios, seminarios, batallones). La otitis, faringitis y eritema multiforme acompañan con cierta frecuencia a M. pneumoniae.

\section{NAC por Haemophilus influenzae}

Se ha descrito más frecuentemente en pacientes con EPOC grave o fumadores. La resistencia adquirida más relevante en esta especie es a las aminopenicilinas mediadas por betalactamasas, que se puede evitar por la combinación de un inhibidor de belactamasas, como el ácido clavulánico y sulbactan a los betalactamicos. Este tipo de belactamasas del $H$. influenzae no afecta la actividad de la cefalosporinos de segunda y tercera generación. Los macrolidos al igual que las quinolonas, tienen acción sobre este agente.

\section{NAC por Staphylococcus aureus}

Es una causa relativamente poco frecuente de neumonía, pero su relevancia ha aumentado debido a la aparición de cepas resistentes a la meticilina (SARM-AC), cuya frecuencia de infecciones es cada vez más frecuente en nuestro medio. Dada la gravedad del cuadro clínico, se debe considerar su diagnóstico diferencial en aquellos pacientes que ingresan al servicio de urgencias con neumonía grave. 


\section{NAC en mayores de 65 años}

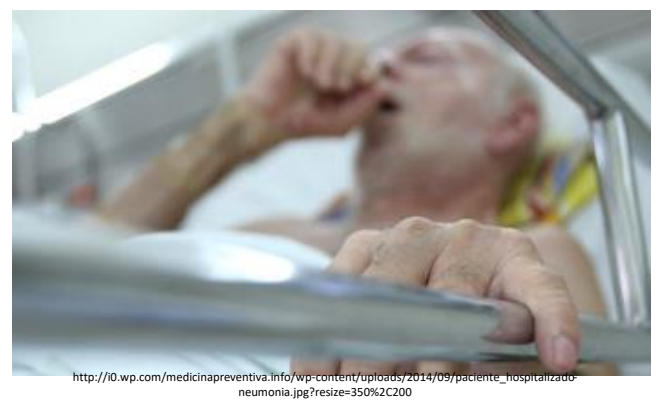

Se considera causa frecuente de hospitalización y mortalidad. Un $10 \%$ de ellos presenta complicaciones del orden de derrame, sepsis y atelectasias. Un $20 \%$ son considerados como NAC grave que requiere tratamiento en UCI, de los cuales, un $30 \%$ son sometidos a respiración mecánica asistida, con supervivencia hasta de 50 \% en mayores de 90 años, resultado que apoya la medida. El grupo más afectado en NAC en mayores de 65, son los hombres entre 75-80 años. En los grupos de Neumonía severa y Neumonía en mayores de 65 años, después de $S$. pneumoniae, la etiología más frecuente está determinada por Bacilos Gram Negativos.

Como los ancianos tienen mayor número de episodios de broncoaspiración que los jóvenes, es importante también tener en cuenta a los anaerobios que colonizan la boca, como otra posible etiología (ACNCT).

\section{NAC y embarazo}

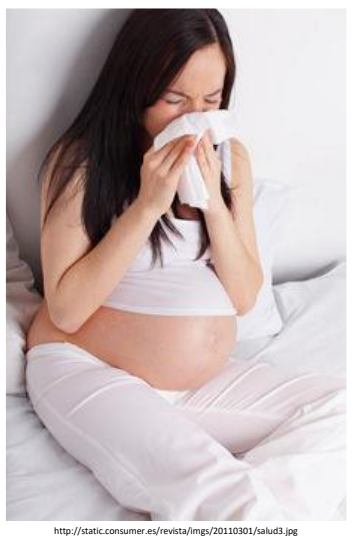

Los cambios fisiológicos, inmunológicos y hormonales que se producen durante el embarazo, aunados en ocasiones al uso de esteroides para maduración fetal, son circunstancias que predisponen a NAC, la cual no es muy bien tolerada en este grupo de pacientes, acompañándose en ocasiones de complicaciones como empiema, neumotórax, fibrilación auricular y taponamiento pericárdico; hasta un $20 \%$ puede requerir ventilación mecánica asistida. El aumento de parto prematuro, bajo peso al nacer y aumento en el número de tactos vaginales se han visto asociados con la NAC. Las medidas diagnósticas y el tratamiento de NAC en embarazadas deben apegarse a las guías actuales de tratamiento de la NAC en adultos. La radiografía con abdomen protegido siempre debe hacer parte del armamentario diagnóstico. 


\section{Evolución}

\section{a. Cuándo pasar antibiótico a vía oral}

Tan pronto se logre la mejoría clínica dada por temperatura $<37.8$, FC $<100, \mathrm{FR}<24$, TA sistólica $>90 \mathrm{mmHg}$ por más de ocho horas sin vasopresores, enfermedades concomitantes estabilizadas, capacidad para la ingestión oral y ausencia de compromiso mental.

No es fácil determinar la probabilidad de respuesta inapropiada al tratamiento inicial, sin embrago, entre el $6 \%$ y $15 \%$ de los casos pueden presentar curso insidioso $(21,60,69)$. La presencia de fiebre o las manifestaciones de deterioro después de 48 horas de tratamiento, deben conducir a la sospecha de empiema, resistencia a los antibióticos, neumonía por atípicos presencia de tuberculosis o micosis, o de otra enfermedad que no sea neumonía (Ca bronquioloalveolar, por ejemplo).

\section{b. ¿Cuáles son los criterios que señalan alta probabilidad de requerir atención en UCI?}

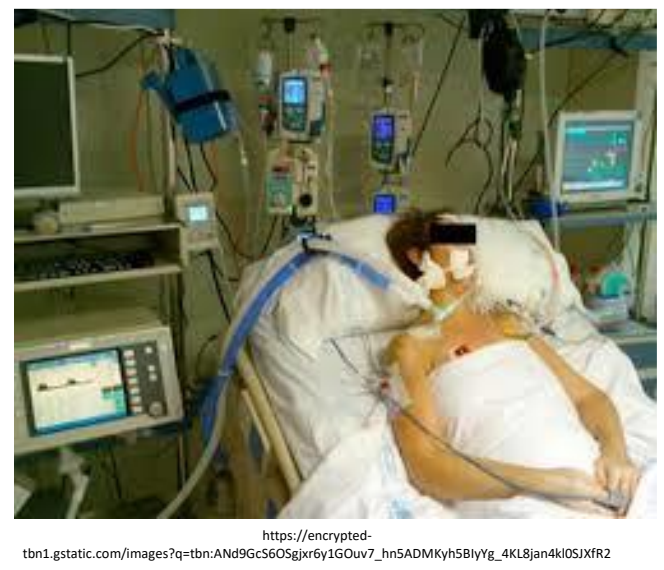

Si se presentan tres o más de los siguientes criterios se debe evaluar la necesidad de traslado a UCI (Nivel de evidencia II, grado de recomendación B) (37).

Alerta - Ingreso a Cuidados Intensivos:

- Hipotensión a pesar de la reanimación hidroelectrolítica apropiada.

- Hipotermia.

- Frecuencia respiratoria elevada (>30 respiraciones/min).

- Alteración de conciencia (confusión).

- Relación PaO2/FiO2 <250.

- Leucopenia (<4000).

- Trombocitopenia (<100 x 109/ L).

- Nitrógeno uréico en sangre $\geq 20 \mathrm{mmol} / \mathrm{L}$ ).

- Consolidación multilobar.

c. ¿Cuáles son las condiciones necesarias para el egreso y cuáles las recomendaciones?

- Apropiada tolerancia a vía oral durante las últimas 24 horas.

- Estado mental normal. 
- Resolución de fiebre durante las últimas 24 horas, o no inferior a $37,8^{\circ} \mathrm{C}$.

- Frecuencia cardiaca < 90 por minuto durante las últimas 24 horas.

- Resolución progresiva de signos de dificultad respiratoria durante las últimas 48 horas.

- No hipotensión durante las últimas 24 horas.

- Ausencia de hipoxia y apropiada saturación ( $\geq 90 \%$ ) verificable, al menos cada 8 horas, durante las últimas 24 horas. Ahora bien, tal como ha sido identificad por Majumdar (51) en su estudio prospectivo en 2923 pacientes con neumonía adquirida en la comunidad, dar de alta del servicio de urgencias a pacientes con una Sa02 menor del $90 \%$, se asoció a tasas de mortalidad más altas (6\%) en comparación con la mortalidad en quienes tenían saturación mayor a $90 \%$, cuya mortalidad fue de $1 \%(p<0.001)$. Igual sucedió con el índice de readmisiones $18 \%$ versus $7 \%$ $(p<0.001)$. Esto constituye una probabilidad conjunta para desenlace adverso (odds ratio readmisión - muerte) de 1,7 IC del $95 \% 1,1-2,8, \mathrm{p}=0,032$ ). En aquellos pacientes con Sa02 del $92 \%$ o más, la asociación con eventos adversos (readmisión - muerte) no se presentó. Por lo tanto, es necesario realizar apropiadamente la oximetría de pulso y no subestimar saturaciones inferiores a $90 \%$, en ningún caso.

- Sin evidencia clínica de bacteriemia.

- Comorbilidad no descompensada.

- Apoyo familiar o red de apoyo en domicilio.

\section{RECOMENDACIONES PARA EL EGRESO}

- Consumir líquidos siempre que no haya razones para restringirlos.

- No fumar.

- Vacuna contra neumococo e influenza.

- Evitar cambios bruscos de temperatura y/o corrientes de aire.

- Continuar antibióticos según lo indicado en la prescripción de egreso.

- Consultar si reaparece fiebre o hay deterioro del estado general.

- Lavado de manos durante 20 segundos, después de ir al baño y antes de las comidas.

\section{BIBLIOGRAFÍA}

(1) Bartlett JG, Dowell SF, Mandell LA, et al. Practice guidelines for the management of community-acquired pneumonia: Guidelines from the Infectious Disease Society of America. Clin Infect Dis. 2000; 31:347-382.

(2) Niederman M S, Bass J B Jr, Campbell G D, Fein A M, Grossman R F, Mandell L A, et al. American Thoracic Society guidelines for the initial management of adults with communityacquired pneumonia: diagnosis, assessment of severity, and initial antimicrobial therapy. American Thoracic Society. Medical Section of the American Lung Association. Am Rev Respir Dis 1993; 148: 1418-26.

(3) Woodhead M. Community-acquired Pneumonia Guidelines. An international comparison. A view from Europe. Chest 1998; 113: S183SS187.

(4) Calmaggi A, Clara L, González Arzac M, López Furst M J, Levy Hara G. Guías para el diagnóstico y tratamiento de la neumonía adquirida en la comunidad en adultos. Infect Microbiol Clin 2000

(5) Bantar, C, Bavestrello, L, Curcio, D, Jasovich A, Absi R, Bagnulo H, et al. Acute community-acquired pneumonia in adults: guidelines for initial antimicrobial therapy based on local evidence from a South American Working Group (ConsenSur). J Chemother 2002; 14 (Suppl 4): $1-22$.

(6) Mandell L, Wunderink R, Anzueto A, Bartlett J G, Campbell G D, Dean N C, et al. Infectious Diseases Society of America/American Thoracic Society Consensus Guidelines on the Management of Community-Acquired Pneumonia in Adults. Clin Infect Dis 2007; 44: 27-72.

(7) Diehr P, Wood RW, Bushyhead J, et al. Prediction of pneumonia in outpatients with acute cough-a statistical approach. J Chronic Dis $1984 ; 37: 215-25$.

(8) Spiteri MA, Cook DG, Clarke SW. Reliability of eliciting physical signs in examination of the chest. Lancet 1988; $1: 873-5$.

(9) Heckerling PS, Tape TG, Wigton RS, et al. Clinical prediction rule for pulmonary infiltrates. Ann Intern Med. 1990; 113:664-670.

(10) Metlay JP, Schulz R, Li YH, et al. Influence of age on symptoms at presentation in patients with community-acquired pneumonia. Arch Intern Med 1997; 157:1453-9.

(11) Metlay JP, Kapoor WN, Fine MJ. Does this patient have community-acquired pneumonia? Diagnosing pneumonia by history and physical examination. JAMA 1997; 278:1440-5.

(12) Saldías F., Méndez J., Ramírez D, Díaz O. Valor predictivo de la historia clínica y el examen físico en el diagnóstico de la neumonía del

Carta Comunitaria. Vol. 23. Número 132. Mayo-Junio de 2015 
adulto adquirida en la comunidad. Revisión de la literatura. Rev Med Chile 2007; 135: 517-528.

(13) Levy M, Dromer F, Brion N, Leturdu F, Carbon C. Community-acquired pneumonia: importance of initial noninvasive bacteriologic and radiographic investigations. Chest 1988; 93: 43-8.

(14) Liapikou A, Ferrer M, Polverino E, Balasso V, Esperatti M, Piñer R, et al. Severe Community-acquired pneumonia: Validation of the Infectious Diseases Society of America/American Thoracic Society Guidelines to Predict an Intensive Care Unit Admission. Clin Infect Dis 2009; 48: 377-85.

(15) Valencia M, Badia J R, Cavalcanti M, Ferrer M, index class v patients with community-acquired pneumonia: characteristics, outcomes, and value of severity scores. Chest 2007; 132: 515-22.

(16) Renaud B, Coma E, Labarere J, Hayon J, Roy P M, Boureaux H, et al. Routine use of the Pneumonia Severity Index for guiding the siteof-treatment decision of patients with pneumonia in the emergency department: a multicenter, prospective, observational, controlled cohort study. Clin Infect Dis 2007; 44: 41-9.

(17) Barlow G, Nathwani D, Davey P. The CURB65 pneumonia severity score outperforms generic sepsis and early warning scores in predicting mortality in community-acquired pneumonia. Thorax 2007; 62:253-9.

(18) Myint PK, Kamath AV, Vowler SL, Maisey DN, Harrison BD. Severity assessment criteria recommended by the British Thoracic Society (BTS) for community-acquired pneumonia (CAP) and older patients. Should SOAR (systolic blood pressure, oxygenation, age and respiratory rate) criteria be used in older people? A compilation study of two prospective cohorts. Age Ageing 2006; 35: $286-91$.

(19) Bantar C et al. Neumonía aguda adquirida en la comunidad en adultos: Actualización de los lineamientos para el tratamiento antimicrobiano inicial basado en la evidencia local del Grupo de Trabajo de Sudamérica (ConsenSur II) Rev Chil Infect 2010; 27 (Supl 1): 9-38.

(20) Van der Eerden MM, Vlaspolder F, de Graaff CS, et al. Comparison between pathogen directed antibiotic treatment and empirical broads pectrum antibiotic treatment in patients with community acquired pneumonia: a prospective randomised study. Thorax 2005; 60:672-8.

(21) Menendez R, Torres A, Zalacain R, et al. Risk factors of treatment failure in community acquired pneumonia: implications for disease outcome. Thorax 2004; 59:960-5.

(22) Mundy LM, Leet TL, Darst K, Schnitzler MA, Dunagan WC. Early mobilization of patients hospitalized with community-acquired pneumonia. Chest. 2003; 124 (3):883-889.

(23) Eliakim-Raz Noa, Robenshtok E, Shefet D, Gafter-Gvili A, Vidal L, Paul M, Leibovici L. Empiric antibiotic coverage of atypical pathogens for community-acquired pneumonia in hospitalized adults. Cochrane Database Syst Rev. 2012 Sep 12;9.

(24) Lim WS, Baudouin SV, George RC, et al. Pneumonia Guidelines Committee of the BTS Standards of Care Committee. BTS guidelines for the management of community acquired pneumonia in adults: update 2009. Thorax 2009; Vol. 64 (Suppl 3)

(25) Jasovich A, Soutric J, Morera G, Mastruzzo M, Vesco E, Izaguirre M, et al. Efficacy of amoxicillin-sulbactam, given twice-a-day, for the treatment of communityacquired pneumonia. A clinical trial based on a pharmacodynamic model. J Chemother 2002; 14: 591-6.

(26) Aubier M, Verster R, Regamey C, Geslin P, Vercken J B. Once-daily sparfl oxacin versus high-dosage amoxicillin in the treatment of community-acquired, suspected pneumococcal pneumonia in adults. Clin Infect Dis 1998; 26:1312-20.

(27) O'Doherty B, Dutchman D A, Pettit R, Maroli A. Randomized, double-blind, comparative study of grepafl oxacin and amoxycillin in the treatment of patients with community-acquired pneumonia. J Antimicrob Chemother 1997; 40 (Suppl A): 73-81.

(28) Tremolieres F, de Kock F, Pluck N, Daniel R. Trovafl oxacin versus high-dose amoxicillin ( $1 \mathrm{~g}$ three times daily) in the treatment of community-acquired bacterial pneumonia. Eur J Clin Microbiol Infect Dis 1998; 17: 447-53.

(29) Gleason PP, Kapoor WN, Stone RA, et al. Medical outcomes and antimicrobial costs with the use of the American Thoracic Society guidelines for outpatients with community-acquired pneumonia. JAMA 1997; 278:32-9.

(30) Ailani RK, Agastya G, Mukunda BN, et al. Doxycycline is a cost-effective therapy for hospitalized patients with community-acquired pneumonia. Arch Intern Med.1999; 159:266-70.

(31) Teh B, Grayson ML, Johnson PD, Charles PG. Doxycycline vs. macrolides in combination therapy for treatment of community-acquired pneumonia. Clin Microbiol Infect 2012.

(32) Choudhury G, Mandal P, Singanayagam A, et al. Seven-day antibiotic courses have similar efficacy to prolonged courses in severe community-acquired pneumonia- a propensity-adjusted analysis. Clin Microbiol Infect. 2011; 17:1852-8.

(33) Avdic $E$, Cushinotto LA, Hughes AH, et al. Impact of an antimicrobial stewardship intervention on shortening the duration of therapy for community-acquired pneumonia. Clin Infect Dis. 2012; 54(11):1581-7.

(34) Aliberti S, Blasi F, Zanaboni AM, et al. Duration of antibiotic therapy in hospitalised patients with community-acquired pneumonia. Eur Respir ]. 2010; 36:128-34.

(35) Halm EA, Fine MJ, Marrie TJ, et al. Time to clinical stability in patients hospitalized with community-acquired pneumonia: implications for practice guidelines. JAMA. 1998; 279:1452-7.

(36) Carratala J, Garcia-Vidal C, Ortega L, et al. Effect of a 3-step critical pathway to reduce duration of intravenous antibiotic therapy and length of stay in community-acquired pneumonia. Arch Intern Med. 2012; 172(12):922-8.

(37) Menendez T, Torres A, Rodríguez de Castro F, et al. Reaching stability in community- acquired pneumonia: the effects of the severity of disease, treatment, and the characteristics of patients. Clin Infect Dis. 2004; 39:1783-90.

(38) Dimopoulos G, Matthaiou DK, Karageorgopoulos DE, et al. Short versus long-course antibacterial therapy for community-acquired pneumonia: a meta-analysis. Drugs. 2008; 68(13):1841-54.

(39) Shefet $D$, Robenshtok E, Paul M, Leibovici L. Empirical atypical coverage for inpatients with community-acquired pneumonia: systematic review of randomized controlled trials. Arch Intern Med 2005; 165:1992-2000.

(40) Mills GD, Oehley MR, Arrol B. Effectiveness of b-lactam antibiotics compared with antibiotics active against atypical pathogens in nonsevere community acquired pneumonia: meta-analysis. BMJ 2005; 330:456-60.

(41) El Solh AA, Sikka P, Ramadan F, Davies J. Etiology of severe pneumonia in the very elderly. Am J Respir. Crit. Care Med 2001; 163: 64551.

(42) Luna CM, Famiglietti A, Absi R, et al. Community-acquired pneumonia: etiology, epidemiology, and outcome at a teaching hospital in Argentina. Chest 2000; 118:1344-54.

(43) Leroy O, Santre C, Beuscart C, et al. A five-year study of severe community-acquired pneumonia with emphasis on prognosis in patients admitted to an intensive care unit. Intensive Care Med 1995; 21:24-31.

(44) Sapira JD. The Art and Science of Bedside Diagnosis. Baltimore, MD: Williams \& Wilkins; 1990. 13. Forgacs P. Lung sounds. Br J Dis 
Chest. 1969; 63(1):1-12.

(45) Marrie T, Lau C, Wheeler S, Wong C J, Feagan B G. Predictors of symptom resolution in patients with community-acquired pneumonia. Clin Infect Dis 2000; 31: 1362-7.

(46) Metlay J P, Atlas S J, Borowsky L H, Singer D E. Time course of symptom resolution in patients with community-acquired pneumonia. Respir Med 1998; 92: 1137-42.

(47) Okimoto N, Yamato K, Kurihara T. Clinical predictors for the detection of community-acquired pneumonia in adults as a guide to ordering chest radiographs. Respirology.2006-11, 322-324.

(48) Mandell LA, Marrie TJ, Grossman RF, Chow AW, Hyland RH. Canadian guidelines for the initial management of community-acquired pneumonia: an evidence-based update by the Canadian Infectious Diseases Society and the Canadian Thoracic Society. The Canadian Community-Acquired Pneumonia Working Group. Clinical Infectious Diseases 2000; 31:383-421.

(49) Levy ML, Le Jeune I, Woodhead MA, Macfarlaned JT, Lim WS; British Thoracic Society Community Acquired Pneumonia in Adults Guideline Group. Thorax October 2009. Vol 64 Supplement III.

(50) Woodhead M, Blasi F, Ewig S, Huchon G, Ieven M, Ortqvist A, et al. Guidelines for the management of adult lower respiratory tract infections. Eur Respir J 2005; 26: 1138-80.

(51) Majumdar SR, Eurich DT, Gamble JM, et al. Oxygen saturations less than $92 \%$ are associated with major adverse events in outpatients with pneumonia: a population-based cohort study. Clin Infect Dis 2011; 52:325-31.

(52) Liapikou A, Ferrer M, Polverino E, Balasso V, Esperatti M, Piñer R, et al. Severe Community-acquired pneumonia: Validation of the Infectious Diseases Society of America/American Thoracic Society Guidelines to Predict an Intensive Care Unit Admission. Clin Infect Dis 2009; 48: 377-85.

(53) Neill A M, Martín J R, Weir R, Anderson R, Cherevshsky A, Epton M J, et al. Communityacquired pneumonia: aetiology and usefulnesof severity criteria on admission. Thorax 1996; $51: 1010-6$.

(54) Fine M J, Auble T E, Yealy D M, Hanusa B H, Wiessfeld L A, Singer D E, et al. A prediction rule to identify low-risk patients with communityacquired pneumonia. N Engl J Med 1997; 336: 243-50.

(55) Fine M J, Hough L J, Medsger A R, Li Y H, Ricci E M, Singer D E, et al. The hospital admission decision for patients with communityacquired pneumonia: results from the pneumonia Patient Outcomes Research Team cohort study. Arch Intern Med 1997; 157:36-44.

(56) García E, Marcos MA, Mensa J, et al. Assessment of the usefulness of sputum culture for diagnosis of community-acquired pneumonia using the PORT predictive scoring system. Arch Intern Med 2004; 164:1807-11.

(57) Campbell SG, Marrie TJ, Anstey R, Dickinson G, Ackroyd S. The contribution of blood cultures to the clinical management of adult patients admitted to the hospital with community-acquired pneumonia: a prospective observational study. Chest 2003; $123: 1142$.

(58) Waterer GW, Wunderink RG. The influence of the severity of community- acquired pneumonia on the usefulness of blood cultures. Respir Med 2001; 95:78-82.

(59) Low DE, Green K, et al. Predicting antimicrobial resistance in invasive pneumococcal infections. Clin Infect Dis 2005; 40:1288-97.

(60) Arancibia F, Ewig S, Martinez JA, et al. Antimicrobial treatment failures in patients with community-acquired pneumonia. Am J Respir Crit Care Med 2000; 162:154-60.

(61) Van der Eerden MM, Vlaspolder F, de Graaff CS, et al. Comparison between pathogen directed antibiotic treatment and empirical broads spectrum antibiotic treatment in patients with community acquired pneumonia: a prospective randomized study. Thorax 2005; 60:6728.

(62) British Thoracic Society. Guidelines for the management of community acquired pneumonia in adults. Thorax 2001; 56 (Suppl 4:IV):164.

(63) Niederman MS, Mandell LA, Anzueto A, Bass JB, Broughton WA, Campbell GD. Guidelines for the management of adults with communityacquired pneumonia. Diagnosis, assessment of severity, antimicrobial therapy, and prevention. American Journal of Respiratory and Critical Care Medicine 2001; 163:1730-54.

(64) Hedlund J, Stralin K, Ortqvist A, Holmberg H. Swedish guidelines for the management of community-acquired pneumonia in immunocompetent adults. Scandinavian Journal of Infectious Diseases 2005; 37:791-805.

(65) Woodhead M, Blasi F, Ewig S, Huchon G, Ieven M, Ortqvist A, et al. Guidelines for the management of adult lower respiratory tract infections. European Respiratory Journal 2005; 26:1138-80.

(66) Halm EA, Fine MJ, Marrie TJ, et al. Time to clinical stability in patients hospitalized with community-acquired pneumonia: implications for practice guidelines. JAMA. 1998; 279:1452-7.

(67) Avdic E, Cushinotto LA, Hughes AH, et al. Impact of an antimicrobial stewardship intervention on shortening the duration of therapy for community-acquired pneumonia. Clin Infect Dis. 2012; 54(11):1581-7.

(68) Ramirez JA. Worldwide perspective of the quality of care provided to hospitalized patients with community-acquired pneumonia: results from the CAPO international cohort study. Semin Respir Crit Care Med. 2005; 26(6):543-52.

(69) Roson B, Carratala J, Fernandez N, Tubau F, Manresa F, Gudiol F. Causes and factors associated with early failure in hospitalized patients with community-acquired pneumonia. Arch Intern Med 2004; 164:502-8.

(70) Tydeman DE. An investigation into the effectiveness of physiotherapy in the treatment of patients with community acquired pneumonia. Physio Pract 1989; 5:75-8.

(71) Chalmers JD, Taylor JK, Mandal P, et al. Validation of the Infectious Disease Society of America/America Thoracic Society minor criteria for intensive care unit admission in community-acquired pneumonia patients without major criteria or contraindications to intensive care unit care. Clin Infect Dis 2011; 53:503-11.

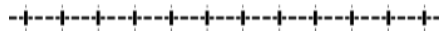

Carta Comunitaria. Vol. 23. Número 132. Mayo-Junio de 2015 